\title{
KEBHINEKAAN BANGSA INDONESIA: URGENSI DAN RELEVANSINYA DALAM ERA REVOLUSI INDUSTRI 4.0
}

\author{
Oleh: \\ I.B.G. Yudha Triguna \\ ajiktriguna@unhi.ac.id \\ Universitas Hindu Indonesia \\ Denpasar
}

Proses Review 19-28 September, Dinyatakan Lolos 2 Oktober 2019

\begin{abstract}
The identity issues, in fact, are almost always capitalized, instrumentalized, and mobilized in every political contestation, both at the local and national level so that community polarization is not only based on political choices, but also primordial identity. The transformation of diversity into national identity implies the importance of parsing the relation of ethnicity and other primordial sentiments to nationalism. Pride of primordial identity must go hand in hand with the pride of a diverse nation. Building social cohesion in the reality of a plural nation finds its urgency and relevance for the successful transformation of the Indonesian nation into a developed, just, prosperous, and dignified country in the eyes of the world.
\end{abstract}

Keywords: Diversity, Identity, Indonesia, Industrial Revolution 4.0

\begin{abstract}
Abstrak
Isu-isu SARA dan identitas, bahkan hampir selalu dikapitalisasi, diinstrumentalisasi, dan dimobilisasi dalam setiap kontestasi politik, baik pada tingkat lokal maupun nasional sehingga polarisasi masyarakat tidak hanya didasari pilihan politik, tetapi juga identitas primordial. Transformasi kebhinekaan ke dalam identitas nasional mengisyaratkan pentingnya mengurai relasi etnisitas dan sentimen primordial lainnya dengan nasionalisme. Kebanggaan terhadap identitas primordial harus berjalan seiring dengan kebanggaan berbangsa yang berbhineka. Membangun kohesi sosial dalam realitas bangsa yang plural menemukan urgensi dan relevansinya bagi keberhasilan transformasi bangsa Indonesia menjadi negara yang maju, adil, sejahtera, dan bermartabat di mata dunia.
\end{abstract}

Kata Kunci: Kebhinekaan, Identitas, Indonesia, Revolusi Industri 4.0 


\section{PENDAHULUAN}

"We are at the beginning of a revolution that is fundamentally changing the way we live, work, and relate to one another. In its scale, scope and complexity, what I consider to be the fourth industrial revolution is unlike anything humankind has experienced before" (Schwab, 2016).

Revolusi industri 4.0 mengisyaratkan sebuah transformasi fundamental pada segala lini kehidupan masyarakat. Era ini menuntut seluruh bangsa dan negara untuk menyiapkan sumber daya manusia yang kompeten, serta piranti teknologi yang canggih agar mampu bersaing dalam dunia global. Dibutuhkan perhatian dan energi besar untuk menjadi bangsa yang unggul dalam revolusi industri keempat. Namun sayangnya, perhatian dan energi bangsa Indonesia justru terkuras untuk mengurusi masalah kebhinekaan yang tak kunjung usai, bahkan ekskalasinya cenderung meningkat belakangan ini. Hasil survei yang dirilis Tim Pusat Penelitian Politik LIPI, menunjukkan bahwa politisasi SARA (suku, ras, agama, dan antargolongan) dan identitas, menjadi potensi tertinggi yang dapat menghambat penyelenggaraan pemilu 2019 dan berdampak pada konsolidasi demokrasi di Indonesia (Kompas.com, 07 Agustus 2018) ${ }^{1}$.

Ekskalasi politisasi SARA dan identitas memang cenderung meningkat terutama sejak Pilkada DKI Jakarta 2017. Isu-isu SARA dan identitas, bahkan hampir selalu dikapitalisasi, diinstrumentalisasi, dan dimobilisasi dalam setiap kontestasi politik, baik pada tingkat lokal maupun nasional sehingga polarisasi masyarakat tidak hanya didasari pilihan politik, tetapi juga identitas primordial. Politik identitas dan bangkitnya primodialisme belakangan ini menjadi alarm 'darurat SARA' yang menandai bahwa kebhinekaan sebagai identitas bangsa Indonesia sedang terancam (Lindawati, 2017:17-18). Beriringan dengan itu, juga

1 Hasil survei: Politisasi SARA dan identitas $(23,6 \%)$; konflik horizontal pendukung paslon $(12,3 \%)$; gangguan keamanan (10,4\%), kekurangsiapan penyelenggara pemilu $(6,6 \%)$; dan ketidaknetralan penyelenggara Pemilu (5,7\%). hipokrisi (kemunafikan sosial) dan vigilantilisme (ujaran kebencian) terus menghiasi ruangruang publik, khususnya media sosial yang saat ini menjadi panggung terpopuler. Kondisi kebhinekaan bangsa yang sedang terkoyak ini penting disikapi oleh seluruh komponen bangsa dengan menegaskan kembali nilai-nilai keindonesiaan dan mengelolanya sebagai kekuatan untuk menatap masa depan Indonesia yang lebih baik, terutama menghadapi revolusi industri 4.0 yang telah bergulir.

\section{TEORI}

Negara dan bangsa Indonesia merupakan hasil kesepakatan bersama dari seluruh rakyat Indonesia yang beraneka ragam suku, ras, budaya, dan agamanya. Kesepakatan tersebut tidak lahir begitu saja, tetapi melalui proses historis yang panjang. Perlawanan terhadap penjajah yang awalnya bersifat parsial mulai diarahkan menjadi perlawanan kolektif dengan membangkitkan semangat kebangsaan (nasionalisme), di antaranya melalui Sumpah Pemuda yang menciptakan konsensus nasional "satu tanah air, bangsa, dan bahasa". Puncak perjuangan bangsa Indonesia untuk meraih kemerdekaannya ditandai dengan Proklamasi Kemerdekaan 17 Agustus 1945 sebagai tonggak sejarah terbentuknya Negara Kesatuan Republik Indonesia, sekaligus menjadi rumah baru bangsaIndonesiadengansegalakebhinekaannya.

Realitas sosiohistoris tersebut menunjukkan bahwa Indonesia memilih negara-bangsa (nation state) sebagai gagasan bernegaranya. Menurut Majid (2004:42), negara-bangsa adalah gagasan tentang negara yang didirikan bagi seluruh bangsa atau untuk seluruh umat, berdasarkan kesepakatan bersama yang menghasilkan hubungan kontraktual dan transaksional terbuka antara pihak-pihak yang mengadakan kesepakatan itu. Konsep ini mengindikasikan bahwa hubungan antar-ras, etnis, budaya, daerah, dan agama di Indonesia, tidak dibangun dalam skema superior-inferior, tetapi lebih bersifat kolegial. Semua terikat pada kontrak kesepakatan yang sama sebagai sebuah bangsa dengan hak, kewajiban, dan tanggung jawab yang setara satu sama lain. Di sini, nasionalisme menjadi ideologi sekaligus fondasi 
yang paling kokoh untuk merajut kebhinekaan dengan menumbuhkan semangat rela berkorban, serta ketulusan untuk mengabdi kepada bangsa dan negara.

Kebhinekaan yang bersifat warisan 'given', kemudian harus dipandang sebagai realitas yang dibangun 'construct' dalam konteks negarabangsa. Hal ini karena kebhinekaan yang diwarisi serta merta harus ditransformasikan ke dalam identitas nasional sebagai sebuah bangsa. Transformasi ini tidak selalu berjalan mulus mengingat negara dan bangsa Indonesia lahir melalui revolusi politik secara tiba-tiba kemerdekaan - yang boleh jadi mendahului kesiapan untuk menyediakan piranti-piranti negara. Terbukti bahwa penetapan bentuk, dasar, dan konstitusi negara, ternyata menyisakan persoalan ideologis karena tidak sepenuhnya mampu mengakomodasi kepentingan elemen bangsa yang berbeda-beda. Apalagi dalam perjalanan sejarahnya, juga tergoreskan luka berupa ketimpangan sosial, ketidakmerataan pembangunan, tirani minoritas, dan sebagainya. Dalam hal ini, pandangan Anderson (1999) tentang bangsa dan nasionalisme penting direnungkan kembali. Menurut Anderson (1999:21), bangsa adalah komunitas imajiner (imagined community), sebuah komunitas politik yang mencakup jutaan orang, yang tidak pernah saling mengenal dan mungkin tidak akan pernah melihat, tetapi tetap diharapkan membayar pajak, memberi pengabdian, bahkan mengorbankan nyawanya demi bangsa.

Transformasi kebhinekaan ke dalam identitas nasional mengisyaratkan pentingnya mengurai relasi etnisitas dan sentimen primordial lainnya dengan nasionalisme. Kedua konsep ini sebenarnya berkerabat, tetapi dalam praktik, perbedaan keduanya sangatlah rumit (Erikson, 1993). Dalam relasi inilah, kebhinekaan menjadi teks sosial yang maknanya tidak stabil, konstruktif, dan senantiasa dipengaruhi berbagai konteks. Bhinneka Tunggal Ika sebagai teks ideal untuk merajut serat-serat perbedaan dalam persatuan, ternyata dalam praktiknya dimaknai berbeda pada setiap orde pemerintahan.

Era Orde Lama menjadikannya wacana populis untuk membangkitan nasionalisme dalam rangka melawan konstelasi kapitalisme dan sosialisme, melalui ide nasionalis, agama, dan komunis. Pada era Orde Baru, pemerintah melakukan penafsiran tunggal terhadap Pancasila sebagai ideologi negara dengan mengambil sikap represif terhadap berbagai isu, ideologi, dan ekspresi budaya yang dipandang mengancam stabilitas nasional melalui Dwifungsi ABRI. Sebaliknya, reformasi mengagendakan otonomi daerah yang menyediakan peluang lebih besar bagi ekspresi etnisitas dan kebijakan politik lokal (Nurkhoiron, 2007:3-5).

Memahami kebhinekaan sebagai teks sosial dalam pergulatan etnisitas dan nasionalisme menegaskan bahwa identitas nasional harus terus menerus diperbarui dan dikembangkan sesuai kondisi perkembangan masyarakat. Hal ini sejalan dengan pandangan Smith (dalam Tilaar, 2004:109) bahwa identitas nasional merupakan kesinambungan reproduksi dan reinterpretasi atas pola nilai, simbol, mitos, dan tradisi yang membentuk warisan bangsa yang unik, serta identifikasi individu terhadap pola dan warisan tersebut beserta unsur-unsur budayanya. Artinya, kebhinekaan dalam identitas nasional merupakan fenomena transformasional yang keberhasilan maupun kegagalannya sangat ditentukan oleh kemampuan suatu bangsa dalam memaknai kebhinekaan itu sendiri, serta bagaimana merajut serat-serat perbedaan itu sebagai kekuatan dalam membangun kehidupan berbangsa dan bernegara.

\section{PEMBAHASAN}

\subsection{Mengelola Kebhinekaan: Tantangan dan Peluang}

Franz Magnis Suseno (2005:216) menjelaskan bahwa Indonesia hanya dapat bersatu, apabila pluralitas yang menjadi kenyataan sosialnya dihormati. Keindonesiaan dibangun bukan untuk menghilangkan identitas khas seluruh komponen bangsa, melainkan agar semuanya dapat menjadi warga negara Indonesia tanpa merasa terasing. Sikap saling menghormati dalam identitas masing-masing dan kesediaan tidak memaksakan pandangan sendiri tentang hidup yang baik pada siapapun merupakan syarat keberhasilan masa depan 
Indonesia. Kebhinekaan akan menjadi modal dasar pembangunan, manakala perbedaan itu dihargai dan dikembangkan dalam berbagai bentuk kerjasama sosial untuk mewujudkan tujuan pembangunan. Artinya, kebhinekaan bangsa Indonesia harus dilihat dan dikelola dengan skema multikulturalisme sehingga perbedaan dapat ditransformasikan sebagai modal budaya (cultural capital) yang produktif bagi pembangunan. Mengingat basis multikulturalisme adalah menggali kekuatan suatu bangsa yang tersembunyi dalam kebudayaan yang berjenis-jenis (Tilaar, 2004:92). Modal budaya inilah yang seharusnya digali dan digalang menjadi kekuatan nasional. Bukan sekedar untuk mengokohkan kebudayaan nasional, melainkan juga agar segenap elemen bangsa dengan nilai-nilai budayanya dapat berkontribusi positif dan berpartisipasi aktif dalam pembangunan secara adil dan setara (Triguna, 2016, 2017).

Meskipun demikian, membangun multikulturalisme dalam bangsa yang plural bukan perkara yang mudah. Mengingat multikulturalisme dan identitas nasional memiliki sisi dasar yang gelap, yakni rentan menjadi sumber konflik dan perpecahan. Kesalahan dalam mendefinisikan identitas nasional acapkali menyebabkan pendelegitimasian dan peminggiran identitas yang lain. Bahaya serius pada masyarakat multikultur karena keanekaragaman nilai, visi tentang kehidupan yang baik, dan interpretasi sejarah dapat menajamkan sekat-sekat perbedaan masyarakat (Parekh, 2007:307). Bertalian erat dengan itu, Tilaar (2004:85) mengemukakantigatantanganmultikulturalisme dewasa ini, yaitu (1) hegemoni Barat di bidang Iptek, politik, ekonomi, sosial, dan budaya melalui wacana modernisasi terutama yang diarahkan kepada negara-negara berkembang; (2) esensialisasi budaya, yakni menggali esensi budaya sendiri yang berpotensi menumbuhsuburkan xenopobhia dan etnosentrisme; dan (3) globalisasi yang berpretensi melunturkan jati diri dan identitas khas setiap bangsa seiring mencairnya batasbatas politik dan kebudayaan.

Ketiga tantangan tersebut menciptakan paradoks keindonesiaan yang berbhineka.
Modernisasi yang mengacu kepada ide-ide kemajuan versi Barat mendorong pola pembangunan yang cenderung mengarah pada transfromasi masyarakat agraris ke industrikapitalis. Pengabaian kepentingan masyarakat lokal dalam pembangunan yang melibatkan relasi pemerintah dan kapitalis di dalamnya, rentan memicu konflik sosial. Ketimpangan sosial antardaerah dan ketidakmerataan pembangunan memperburuk harmonisasi hubungan antara pusat dan daerah. Ketika kesadaran masyarakat terhadap hegemoni Barat tumbuh, justru reaksi yang dilakukan sering berlebihan. Esensialisasi budaya yang direpresentasikan dengan pernyataan bahwa etnis, budaya, dan agama mempunyai nilai keunggulan esensial yang tidak kalah dari Barat, ditunjukkan dengan sikap anti-Barat dan segala yang dipandang sebagai representasinya, termasuk negara. Tumbuhnya etnonationalism dan religionationalism sebagai identitas politik baru 'yang lain' dari nasionalisme negarabangsa membangun imajinasi bahwa negara dengan komunitas etnis atau agama yang seragam akan lebih baik (Suaedy, dkk., 2007:345). Hal ini tidak lepas dari pengaruh globalisasi yang meniscayakan masuknya berbagai ideologi, gaya hidup, dan budaya, melalui saluran informasi yang tanpa batas (Triguna, 2018).

Uraian di atas menegaskan bahwa tantangan terbesar yang dihadapi bangsa Indonesia dalam mengelola kebhinekaan adalah menemukan model terbaik untuk mengkonstruksi identitas nasional dengan implikasi psikis yang menyenangkan. Bagimanapun, identitas nasional tetap diperlukan oleh suatu komunitas politik, seperti bangsa Indonesia. Tidak sekedar untuk membangun kebanggaan berbangsa, tetapi lebih penting dari itu adalah membangun rasa kasih sayang, solidaritas, dan tanggung jawab bersama terhadap kepentingan nasional. Pemahaman tentang identitas nasional harus mampu menyatukan anggotanya pada seputar pemahaman diri, memberi fokus serta energi pada rasa memiliki bersama, membangun citra diri kolektif, mengolah kebaikan-kebaikan yang relevan, memfasilitasi berlangsungnya reproduksi komunitas dan kesinambungan antargenerasi, mempertahankan kesetiaan 
umum, serta menata kehidupan moral dan politik. Ringkasnya, identitas nasional memiliki peranan penting untuk menumbuhkan rasa saling memiliki antara komunitas-komunitas yang beraneka ragam (Parekh, 2008:306).

Kebhinekaan bangsa Indonesia merupakan modal budaya yang mesti dikelola sehingga menjadi kekuatan potensial untuk menjemput masa depan yang lebih baik. Modal budaya ini niscaya dikembangkan menjadi peluangpeluang produktif yang lain, apabila bangsa Indonesia sudah "selesai" dengan kebhinekaannya. Artinya, selama perbedaan etnis, ras, budaya, dan agama masih dianggap sebagai hambatan untuk berinteraksi dan membangun kerja sama sosial, maka sepanjang itu pula bangsa Indonesia akan sulit keluar dari masalah, sekaligus menutup peluang-peluang potensial yang dapat diakses. Dengan kata lain, peluang untuk menjadikan kebhinekaan bangsa Indonesia sebagai kekuatan masa depan akan terbuka, manakala kohesi sosial berhasil dibangun di atas perbedaan-perbedaan. Berkenaan dengan itu, Ritzer et, al. (2000) menekankan pada aspek modal sosial dari kohesi sosial, yaitu suatu keadaan ketika sekelompok orang mampu menunjukkan kemampuan untuk berkolaborasi dan menciptakan iklim perubahan.

Mengelola kebhinekaan dalam kerangka kohesi sosial mensyaratkan terurainya hubungan sosial dikotomis pada lima aspek, sebagai berikut: (1) kebersamaan-isolasi (nilai-nilai bersama, identitas, perasaan, dan komitmen);(2) pengikutsertaan-pengesampingan (kesempatan setara untuk memperoleh akses); (3) partisipasiketidakterlibatan (dalam kehidupan politik, ekonomi, sosial, dan budaya); (4) penerimaanpenolakan (menghargai dan mentolerir perbedaan pada masyarakat majemuk); dan (5) legitimasi-ilegitimasi (adanya institusi-institusi yang berperan sebagai mediator konflik dalam masyarakat majemuk) (Berger-Schmitt, 2000). Dari kelima skema dapat dipahami bahwa kohesi sosial bertujuan memperkuat relasi, interaksi, dan ikatan sosial yang inheren dalam modal sosial (social capital), dengan cara meminimalisasikan perbedaan, ketidakadilan, dan pengesampingan sosial. Apabila kelima aspek tersebut berhasil diurai, maka pembangunan kohesi sosial pada masyarakat plural niscaya akan terwujud.

Masyarakat majemuk dengan tingkat kohesivitas sosial tinggi tentunya memiliki peluang besar untuk melakukan perubahan yang produktif karena di dalamnya terdapat bermacam-macam potensi yang dapat saling melengkapi satu sama lain. Bangsa Indonesia dengan kekayaan sumber daya alam dan keragaman etnis, budaya, serta agamanya mempunyai potensi besar untuk itu. Hanya saja, potensi tersebut tidak berkembang optimal karena perbedaan yang seharusnya menjadi modal sosial konstruktif, justru dijadikan sumber perpecahan sesama anak bangsa. Pencapaian yang tidak sebanding dengan potensi yang dimiliki menunjukkan bentuk kegagalan bangsa Indonesia dalam memanfaatkan potensi kebhinekaan sebagai modal budaya dan modal sosial, alih-alih modal ekonomi.

\subsection{Urgensi dan Relevansinya dalam Revolusi Industri 4.0}

Revolusi industri 4.0 menandai era baru transformasi teknologi, sosial, politik, ekonomi, dan budaya masyarakat dunia yang tidak pernah ditemukan dalam era sebelumnya. Menurut Li, et.al. (2017), prinsip fundamental revolusi industri 4.0 adalah integrasi yang dalam (deep integration) antara kecerdasan (intelligence) dan sistem jaringan (networking system), juga acapkali diartikan Cyber Physical Systems (CPSs) atau industri internet. Beberapa teknologi canggih, seperti kecerdasan buatan (artificial intelligence), robotik, internet of things (IoT), kendaraan otonom, percetakan 3D, nanoteknologi, bioteknologi, dan lainnya telah disiapkan (Schwab, 2016:7). Kecanggihan teknologi ini akan mengkooptasi sebagian peran manusia dalam kehidupannya.

Revolusi industri tidak hanya menawarkan tantangan dalam penyiapan sumber daya manusia yang mampu menguasai teknologi tersebut, tetapi juga revolusi kebudayaan yang sulit diprediksi dampaknya. Disrupsi akibat revolusi industri sebelumnya niscaya terus berlanjut sehingga masyarakat dihadapkan pada ketidakmenentuan mengenai apa yang sedang dan akan terjadi. Situasi disrupsi ini 
telah menjadi perhatian dalam studi yang dilakukan Naisbit (1988; 1990), Huntington (1996), dan Fukuyama (1999). Masyarakat informasi yang oleh Toffler (1980) disebut transisi Gelombang Ketiga (The Third Wave), telah menciptakan perubahan fundamental pada berbagai tatanan sosial yang sulit diprediksikan dan sungguh-sungguh paradoks.

Naisbitt (1988, 1990) menyatakan bahwa keseragaman dan hilangnya identitas kultural adalah mitos globalisasi yang terlalu dibesarbesarkan sebab faktanya, justru lokalitas menunjukkan kebangkitan yang signifikan. Semakna dengan itu, Huntington (1996) dan Fukuyama (1999) menggambarkan bahwa rekonstruksi sosial berdasarkan nilai-nilai kultural dan agama, diprediksi akan memiliki andil lebih besar dalam menentukan integrasi dan kemajuan, juga sebaliknya, konflik dan kemunduran masyarakat. Penegasan identitas kultural dan agama akan semakin potensial dikapitalisasi untuk berbagai kepentingan. Mengingat melalui wacana itulah, perbedaan ditemukan dan dikalkulasikan sebagai keunggulan potensial, manakala bidang-bidang kehidupan yang lain nyaris sepenuhnya seragam. Implikasinya bahwa politik perbedaan, isu-isu lokalitas, dan identitas kultural diprediksi akan semakin menguat gejalanya di tengah dunia yang semakin mengglobal.

Kendati demikian, paradoks global juga membuka ruang dan peluang bagi suatu bangsa untuk menentukan alternatif dalam menyikapi perubahan. Giddens (1998) mengajukan konsep "Jalan Ketiga" (The Third Way) di antara dua kutub ideologi yang paling berpengaruh, yaitu kapitalisme dan sosialisme. Jalan ketiga merupakan upaya strategis dengan mengambil yang baik dan membuang yang buruk dari setiap ideologi untuk membuat ramuan ideologis yang benar-benar sejalan dengan idenitas kultural masyarakat. Di lain pihak, Robertson (1995) menawarkan 'glokalisasi' yang menekankan bagaimana proses-proses global dipengaruhi, bahkan ditumbangkan melalui penerapan, penafsiran dan adaptasi budaya lokal sehingga terjadi interaksi dinamis nilai lokal dan global. Artinya, globalisasi juga menyediakan rentang alternatif bagi masyarakat untuk mengambil peran strategis dalam percaturan global melalui revivalisasi dan revitalisasi kultural.

Revolusi industri 4.0 dengan segala disrupsi yang mengikutinya perlu disikapi secara kritis dalam konteks kebhinekaan bangsa Indonesia. Artikulasi identitas primordial, retaknya identitas nasional, dan politik identitas diprediksi tetap menjadi isu-isu krusial masa depan. Apabila tidak segera diantisipasi dan diupayakan langkah-langkah strategis untuk mengatasinya, maka bukan hanya bangunan keindonesiaan yang terancam runtuh, tetapi Indonesia akan kehabisan energi memasuki revolusi industri 4.0 dan tertinggal jauh dengan bangsa-bangsa lain yang lebih siap. Sebaliknya, revolusi industri memberikan peluang bagi bangsa Indonesia untuk mengoptimalkan kebhinekaan sebagai modal sosial dan budaya memasuki kompetisi dunia masa depan.

\section{PENUTUP}

Menatap revolusi industri 4.0 dengan aneka konsekuensi paradoksnya, kebhinekaan sebagai teks sosial perlu dimaknai terus menerus dalam rangka pengembangan modal sosial dan budaya yang produktif bagi keindonesiaan masa depan. Kebanggaan terhadap identitas primordial harus berjalan seiring dengan kebanggaan berbangsa yang berbhineka. Membangun kohesi sosial dalam realitas bangsa yang plural menemukan urgensi dan relevansinya bagi keberhasilan transformasi bangsa Indonesia menjadi negara yang maju, adil, sejahtera, dan bermartabat di mata dunia.

\section{DAFTAR PUSTAKA}

Anderson, Bennedict. 1999. Komunitas Imajiner: Renungan Tentang Asal-usul dan Penyebaran Nasionalisme. Terjemahan: Omi Intan Naomi. Yogyakarta: Pustaka Pelajar dan INSIST Press. 
Berger-Schmitt. 2000. "Social Cohesion as an Aspect of the Quality of Societies: Concept and Measurement". Eureporting Working Paper. 14.

Erikson, Thomas Hylland. 1993. Etnicity and Nationalisme: Antropological Perspectives. London and Boulder, Colorado: Pluto Press.

Fukuyama, Francis. 1999. The Great Disruption: Human Nature and the Reconstruction of Social Order. London: Profiles Book.

Giddens, Anthony. 1995. The Third Way: The Renewal of Social Democracy. Oxford: Polity Press.

Huntington, Samuel P. 1996. The Clash of Civilization and The Remarking of World Other. New York: Simon \& Schuster.

Kompas.com.(7 Agustus 2018). "Potensi Politisasi SARA dan Identitas akan Hambat Pemilu 2019” dalam https://nasional.kompas.com/read/ 2018/08/07/12084651/potensi-politisasisara-dan-identitas-akan-hambat-pemilu-2019, diakses 5 Semptember 2019.

Li, Guoping; Hou Yun; and Wu Aizhi. 2017. "Fourth Industrial Revolution: Technological drivers, impacts and coping methods." In Chinese Geographical Science. 2017, Vol. 27, p. 626-637.

Lindawati, Debora Sanur. 2017. "Rekonsiliasi Politik Identitas di Indonesia", dalam Majalah Info Singkat Pemerintahan Dalam Negeri, Vol. IX No.10/II/Puslit/Mei/2017, hal. 17-20.

Majid, Nurcholis.2004. Indonesia Kita. Jakarta: Paramadina.

Naisbitt, John. 1988. Global Paradox. New York: William Morrow and Company, Inc.

Nurkhoiron, M. 2007. "Minoritisasi dan Agenda Multikulturalisme di Indonesia: Sebuah Catatan Awal", dalam Hak Minoritas Multikulturalisme dan Dilema Negara Bangsa. Editor: Marsudi Noorsalim, dkk. Jakarta: Yayasan Interseksi/The Interseksi Foundation.

Parekh, Bhiku. 2007. Rethinking Multikulturalism: Keberagaman Budaya dan Teori Politik. Yogyakarta: Kanisius.

Ritzen, Jo, William Esterlay, and Michael Woolcock. 2000. “"Good Politicians" and "Bad Policies": Social Cohesion, Institutions and Growth", in Policy Research Working Paper, Setember, 2448. Switzerland: World Bank.

Schwab, Klaus. 2016. The Fourth Industrial Revolution. Geneva-Switzerland: World Economic Forum. Suaedy, Ahmad, dkk. 2007. Politisasi Agama dan Konflik Komunal Beberapa Isu Penting di Indonesia. Jakarta: The Wahid Institute.

Suseno, Franz Magnis. 2005. Berebut Jiwa Bangsa. Jakarta: Kompas.

Tilaar, H.A.R.2004. Multikulturalisme Tantangan-tantangan Global Masa Depan dalam Transformasi Pendidikan Nasional. Jakarta: Grasindo.

Toffler, Alvin. 1980. The Third Wave. New York: William Morrow and Company, Inc.

Yudha Triguna, Ida Bagus Gde. 2017. "Kearifan Lokal dalam Membangun Nasionalisme dan Keberagaman". Seminar Nasional. Palangkaraya: Institut Agama Hindu Negeri.

Yudha Triguna, Ida Bagus Gde. 2017. "Menjaga Pluralitas Guna Memperkokoh Kebinekaan Tunggal Ikaan Dalam Rangka Ketahanan Nasiona”. Makalah. Jakarta: Dewan Keamanan Nasional (Wantanas).

Yudha Triguna, Ida Bagus Gde. 2017. “Penguatan Legislasi Penghayat Kepercayaan”. Paper. Jakarta: FGD Metro.

Yudha Triguna, Ida Bagus Gde. 2017. Budaya Inspiratif dan Pembangunan Karakter. Denpasar: Denpasar: Pascasarjana Unhi.

Yudha Triguna, Ida Bagus Gde. 2018. "Kepemimpinan dan Nitisastra”. Makalah Seminar Nasional. Denpasar: Kementerian Agama Provinsi Bali.

Yudha Triguna, Ida Bagus Gde. 2019. “Tantangan dalam Membangun Kebersamaan”. Makalah. Denpasar: Kementerian Agama Provinsi Bali. 